\title{
Videojuegos: Incentivos Multisensoriales Potenciadores de las Inteligencias Múltiples en Educación Primaria
}

\section{Esther del Moral Pérez ${ }^{1}$, Laura Carlota Fernández García $^{1}$ y Alba Patricia Guzmán Duque ${ }^{2}$}

${ }^{1}$ Departamento de Ciencias de la Educación, Universidad de Oviedo, Oviedo, España

${ }^{2}$ Programa de Administración de Empresas. Unidades Tecnológicas de Santander. Colombia

\section{España/Colombia}

Correspondencia: Dra. $M^{a}$ Esther del Moral Pérez, Departamento de Ciencias de la Educación, Facultad de Formación del Profesorado y Educación, Universidad de Oviedo. Despacho 210. C/ Aniceto Sela, s/n, 33005 Oviedo. España. E-mail: emoral@uniovi.es

(C) Education \& Psychology I+D+i and Ilustre Colegio Oficial de la Psicología de Andalucía Oriental (Spain) 


\section{Resumen}

Introducción. La investigación se centró en estudiar en qué medida los videojuegos educativos, utilizándolos planificada y sistemáticamente, pueden constituir contextos de aprendizaje propicios para desarrollar las Inteligencias Múltiples (IM) en escolares.

Metodología. Se adoptó una dualidad metodológica: a) cualitativa: evaluación previa y análisis de contenido del videojuego a utilizar en la experiencia, primando su adecuación y correspondencia con las áreas curriculares de primaria; b) experimental: estudio de caso orientado a constatar el posible incremento de las IM en alumnos de Primer Ciclo de Educación Primaria $(\mathrm{N}=101)$ derivado de la implementación del videojuego en el aula durante un curso, utilizando un grupo de control e identificando el nivel alcanzado antes (test) y después de la experiencia (postest) con un instrumento de evaluación.

Resultados. La selección previa del videojuego garantiza la adquisición y refuerzo de numerosos aprendizajes vinculados con los contenidos curriculares de Primaria. Las actividades lúdicas -relacionadas con las ocho inteligencias- suponen retos motivadores para los escolares y ocasiones para potenciar diversas habilidades. Tras la experiencia lúdicoformativa con el videojuego se observó un incremento generalizado en todas las inteligencias, resultando significativas la lógico-matemática, la viso-espacial y la corporal-cinestésica, mejorando las dos primeras más en las niñas, que en los niños.

Conclusiones. Se verificó la hipótesis de partida: la introducción de videojuegos educativos adecuados en las aulas y su explotación sistemática promueve el desarrollo de las IM en escolares de primaria. Especialmente, las operaciones de medida, cálculos matemáticos, recuentos, identificación y clasificación de formas y tamaños, relaciones y correspondencias, junto a actividades que fomentan el cuidado del cuerpo (dieta saludable e higiene personal) presentados de forma lúdica facilitan el aprendizaje e incrementan las IM.

Palabras clave: videojuegos, inteligencias múltiples, motivación, aprendizaje cognitivo y afectivo, habilidades. 


\title{
Videogames: Multisensory Incentives Boosting Multiple Intelligences in Primary Education
}

\begin{abstract}
Introduction. The research was focused on studying to what extent educational video games, using them in a planned and systematic manner, can constitute learning contexts to develop Multiple Intelligences (MI) in school.

Method. Methodological dualism was adopted: a) qualitative: preliminary evaluation and content analysis of the video game used in the experience, prioritizing their suitability and correspondence with the primary curriculum areas; b) experimental: a case study aimed at finding the possible increase of MI in students of First Cycle of Primary Education $(\mathrm{N}=101)$ derived from the implementation of the game in the classroom during an academic year, using a control group and identifying level reached before (test) and after the experience (post-test) with a instrument of evaluation.

Results. The pre-selection of video game ensures the acquisition and reinforcement of many learning linked with the contents of Primary curriculum. Playful activities - related to the eight intelligences - involve motivational challenges for students and opportunities to enhance various skills. After the fun-learning experience with the game was observed a general increase in all intelligences, resulting significant the logical-mathematical, visual-spatial and the bodily-kinesthetic, although the first two improve more in girls than in boys.

Discussion and conclusion. The starting hypothesis was verified, the introduction of appropriate educational video games in classrooms and their systematic exploitation promotes the development of MI in primary school. Especially, the measurement operations, mathematical calculations, counting, identification and classification of shapes and sizes, relationships and correspondences, with activities that promote body care (healthy diet and personal hygiene) presented in a fun way facilitates learning and increases the MI.
\end{abstract}

Keywords: video games, multiple intelligences, motivation, cognitive and affective learning, skills. 


\section{Introducción}

Los videojuegos pueden dividirse, según su finalidad en: comerciales (Grand Theft Auto, Castlevania, etc.), desarrollados para el mero entretenimiento; y, juegos educativos, orientados al aprendizaje (Connolly, Boyle, MacArthur, Hainey \& Boyle, 2012). Entre éstos últimos se encuentran los serious games o juegos serios, creados con fines formativos tanto para el ámbito académico, científico, como para defensa, salud, resolución de conflictos, promoción de cambios sociales, etc. (Schollmeyer, 2006). Potencian el desarrollo de múltiples destrezas y promueven aprendizajes diversos (Lee, Heeter, Magerko \& Medler, 2012), vinculados con la salud, la socialización de la infancia y la adolescencia (Pindado, 2005), etc. Según Wouters, van Nimwegen, van Oostendorp y van der Spek (2013) pueden ser unos instrumentos educativos eficaces, al favorecer la motivación y el aprendizaje (Adams \& Clark, 2014), y constituirse en contextos de aprendizaje en sí mismos, óptimos para el desarrollo de las habilidades del siglo XXI (DiCerbo, 2014), tales como la colaboración, el pensamiento crítico y creativo, la resolución de problemas, las habilidades de razonamiento, el aprender a aprender, la toma de decisiones y la alfabetización digital (Voogt \& Pareja, 2010).

Existen experiencias de integración de los videojuegos en contextos formativos que demuestran que éstos ayudan a adquirir aprendizajes, al simular procesos sociales, y, fomentar la experimentación y la curiosidad (Cortés, García \& Lacasa, 2012; Del Castillo, Herrero, García, Checa \& Monjelat, 2012; Sung \& Hwang, 2013). Por su parte, Robertson (2013) y Vos, van der Meijden y Denessen (2011) señalan que -según su naturaleza, temática y actividades- pueden optimizar aprendizajes al otorgar libertad de acción a los jugadores. Annetta, Minogue, Holmes y Cheng (2009) junto a Hickey, Ingram-Goble y Jameson (2009) afirman que contribuyen a la mejora de la comprensión de conceptos, a la adquisición de habilidades de procesamiento y a la resolución de problemas (Liu, Cheng \& Huang, 2011), propician el desarrollo de habilidades viso-espaciales (Bailey \& West, 2013), y potencian la inteligencia emocional (Acampora, Loia \& Vitiello, 2012; Herodotou, Kambouri \& Winters, 2011).

Así pues, dado su potencial educativo, los serious games pueden ser vehículos idóneos para el desarrollo de las Inteligencias Múltiples (IM) -enunciadas por Gardner (2005)-, definidas como un constructo multidimensional y diverso, integrado por el sumatorio de ocho 
tipos de inteligencia: linguística, musical, lógico-matemática, viso-espacial, corporalcinestésica, interpersonal, intrapersonal y naturalista. Es decir, la inteligencia es concebida como un conjunto de múltiples capacidades susceptibles de modificación e incremento (Antunes, 2005), mejorables bajo estímulos adecuados y actividades específicas para cada inteligencia (Amstrong, 2009), relacionándolas con diferentes áreas curriculares (Fogarty \& Stoehr, 2008; Prieto \& Ballester, 2003; Prieto \& Ferrándiz, 2001). Concretamente, las experiencias de Saricaoglu y Arikan (2009) subrayan los incrementos de las IM en contextos escolares, con el apoyo de entornos virtuales (Riha \& Robles-Piña, 2009), otras con juegos digitales (Sanford \& Madill, 2007; Schaaf, 2012), y otras utilizando videojuegos, ligados específicamente con cada inteligencia, como sucede con el aumento de la lógico-matemática detectado por Li, Ma y Ma (2012).

Así, partiendo de que los serious games pueden convertirse en adecuados estímulos para desarrollar las IM, al estar dotados de componentes multisensoriales que privilegian su éxito como sugerentes contextos de aprendizaje, capaces de atraer la atención del jugador y de propiciar su permanencia en el juego, se hace preciso analizar cómo operan a nivel cognitivo. Sin duda, el uso de atractivos recursos narrativos y técnicos aumenta la implicación o engagement de los usuarios y garantiza su inmersión en el juego. Según Deater-Deckard (2013) el engagement, o predisposición consciente del sujeto para alcanzar determinados objetivos, está relacionado con las emociones positivas derivadas de la superación y el esfuerzo, imprescindibles para convertir el videojuego en un instrumento educativo eficaz. Además, en el proceso de fidelización del usuario inciden otros factores que condicionan su adhesión o engagement, tales como las demandas sociales, los elementos emocionales y las etapas cognitivas; las motivaciones (social, emocional e intelectual); y, los atributos del juego/género (juego colaborativo, demandas y retos) (Sherry, 2013), pues pueden aumentar el interés y las expectativas ante la experiencia lúdica.

La relación entre el engagement y la motivación para mantener el interés del jugador, la expresan Garris, Ahlers y Driskell (2002) a través de un modelo que identifica los aspectos motivadores de los videojuegos que facilitan el aprendizaje:

1. Las dimensiones del juego asociadas a su vertiente instruccional (fantasía, reglas y metas, estímulos sensoriales, desafío, misterio y control).

2. La toma de decisiones del jugador (intereses, disfrute, participación, 
ejecución de la tarea y confianza).

3. El comportamiento del jugador (participación sostenida, esfuerzo, concentración, persistencia y re-engagement o reenganche al juego).

4. La retroalimentación del sistema.

5. Los resultados de aprendizaje logrados (habilidades, aprendizaje cognitivo y afectivo).

En este sentido, tanto los atractivos elementos narrativos -mundos y criaturas fantásticas, lugares misteriosos, recursos mágicos, acertijos y metáforas visuales- que captan la atención del jugador; como la interactividad que le permite tomar decisiones, a partir de ciertas normas o mecanismos para avanzar y alcanzar los objetivos del juego; y, el ágil feedback para recompensarle o ayudarle, etc., son factores claves que contribuyen a su inmersión o estado de flow. Ayudan a concentrar su atención en la actividad, reduciendo su autoconsciencia e incrementando su control en el juego (Esteban, Martínez, Huertas, Meseguer \& Rodríguez, 2014). Sin embargo, la experiencia de disfrute y entretenimiento no le exime de esfuerzo al jugador para terminar con éxito las misiones propuestas y alcanzar las puntuaciones máximas (Del Moral \& Guzmán, 2014).

Del mismo modo, es importante que los recursos estéticos, narrativos y técnicos de los videojuegos propicien la construcción de óptimos escenarios lúdico-educativos para el aprendizaje (Del Moral, 2004), que favorezcan el engagement a partir de la existencia de:

1) Una historia que se muestre como el hilo conductor de la acción, donde el guión, los diálogos entre personajes y la ambientación aumenten el interés y su inmersión.

2) Niveles de dificultad progresiva, el videojuego debe tener un grado de dificultad que plantee retos superables para que el jugador no se dé por vencido y abandone (Islas, Leendertz, Vinni, Sutinen \& Ellis, 2013).

3) Duración del juego adecuada, ni excesivamente larga que sea tedioso y desespere al jugador, ni tan corta que no se garantice un disfrute prolongado.

4) Sonido y efectos sonoros, que den credibilidad y verosimilitud a la acción, junto con efectos dramáticos que envuelvan al jugador emocionalmente.

5) Banda sonora, que enfatice la acción como en las narraciones fílmicas.

6) Doblaje, en varios idiomas que facilita su aprendizaje y el alcance del juego.

7) Apartado gráfico, referido a la calidad y nitidez de la imagen, el diseño (2D, 3D, etc.). 
8) Arte del videojuego, adaptado a las características del público diana: imágenes redondeadas para el público infantil, con diseños artísticos amigables y personajes dulces.

9) Posibilidades de personalización, aspecto demandado por los jugadores, haciendo que la experiencia de juego sea más cercana y propia. La creación del avatar favorece la representación y la identidad del usuario (Lin \& Wang, 2014), y la personalización es una actividad gratificante (Bailey, Wise \& Bolls, 2009), pues los jugadores prefieren diseñar su propio avatar.

10) Control del movimiento preciso de personajes y sus acciones, para facilitar la jugabilidad.

Tras enumerar los componentes multisensoriales de los videojuegos, es importante determinar las oportunidades que ofrecen como contexto de aprendizaje para desarrollar las IM.

Oportunidades de los videojuegos para desarrollar las IM

Algunos videojuegos pueden constituir entornos propicios para potenciar las IM, ello exige conocer qué actividades y mecánicas de juego activan cada inteligencia y qué habilidades implican (Antunes, 2011), además de identificar las características de cada una (Prieto \& Ballester, 2003; Prieto \& Ferrándiz, 2001):

1) La inteligencia lingüística, o capacidad de procesar con rapidez mensajes lingüísticos y comunicarse, puede activarse con videojuegos que impliquen habilidades de descripción, narración, elaboración de conclusiones y resúmenes, conversaciones y todo tipo de prácticas lingüísticas.

2) La inteligencia lógico-matemática, o capacidad de razonamiento deductivo (cálculo, percepción de la geometría espacial, medidas, lógica, cantidades, tamaños, distancias, relaciones entre objetos...), puede potenciarse con videojuegos de puzzles matemáticos, juegos de entrenamiento mental y cálculo (game-training) (Chang, Wu, Weng \& Sung, 2012). Destacan experiencias exitosas con adultos (Basak, Boot, Voss \& Kramer, 2008) y personas con necesidades educativas especiales (Papastergiou, 2009).

3) La inteligencia corporal-cinestésica, o capacidad para usar el cuerpo de manera hábil, es favorecida con el exergaming (wiiU, y XboxOne), simulando prácticas deportivas, mejorando destrezas motoras (Graf, Pratt, Casey, Hester \& Short, 2009).

4) La inteligencia viso-espacial, o habilidad para distinguir formas y objetos, reconocer el entorno, transformar, interpretar $\mathrm{y}$ plasmar percepciones recibidas 
(reconocimiento de mapas, planos, orientación en entornos virtuales, etc.), se desarrolla con videojuegos de alta calidad gráfica, imágenes, vídeos, que requieran habilidades de orientación espacial, interpretación de mapas, diseño y construcción de puzzles y rompecabezas (Los Sims activan esas habilidades al construir viviendas y barrios sobre un plano). Greenfield (2009), Llorca (2009), Yang \& Chen (2010) afirman que algunos videojuegos favorecen las habilidades espaciales, y Korallo, Foreman, Boyd-Davis, Moar y Coulson (2012) describen los efectos cognitivos positivos vinculados a la memoria.

5) La inteligencia naturalista, o habilidad para comprender la naturaleza, clasificar organismos vivos e identificar ecosistemas, se potencia con juegos de experimentación como Norrath (Castronova, 2006) o Spore, creando nuevas especies.

6) La inteligencia musical, o capacidad para percibir, discriminar y expresar formas musicales y sonidos, se entrena con videojuegos de simuladores y sintetizadores musicales, componiendo con diferentes instrumentos, karaoke estilo Sing Star, y juegos de baile (Step Manía o Dance Dance Revolution), activando simultáneamente la corporal cinestésica. Las bandas sonoras de algunos videojuegos, tocadas por prestigiosas orquestas sinfónicas, promueven el gusto por la música.

7) La inteligencia interpersonal, o capacidad de percibir y comprender a otras personas, puede activarse con juegos de simulación social. Las aplicaciones educativas apoyadas en videojuegos pro-sociales consiguen ayudar a jugadores de riesgo (Greitmeyer \& Osswald, 2010), junto a otros que abordan dilemas éticos y propician relaciones asertivas.

8) Y la inteligencia intrapersonal, o capacidad de autoestima, automotivación y autoconcepto positivo. Algunos videojuegos alientan la superación personal y el desarrollo profesional, como juegos de rol y simuladores sociales mediante toma de decisiones, negociación, mediación, etc.

La selección de videojuegos apropiados garantizará el entrenamiento de cada inteligencia siempre que contemple actividades sistemáticas que impliquen el uso interrelacionado de todas ellas, y promuevan aprendizajes mediante la colaboración (Echeverría, García-Campo, Nussbaum, Gil, Villalta, Améstica \& Echeverría, 2011).

\section{Objetivo}

Se busca identificar en qué medida el videojuego educativo Naraba World constituye un contexto de aprendizaje propicio para activar las Inteligencias Múltiples en escolares de Primer Ciclo de Educación Primaria, a partir de su utilización planificada y sistemática. 


\section{Método}

\section{Participantes}

La muestra estuvo integrada por alumnos de 6-7 años ( $\mathrm{N}=101)$ : grupo experimental ( $\mathrm{GE}=81)$, y grupo control $(\mathrm{GC}=20)$, como se presenta en la Tabla 1, a quienes se les midió su nivel de IM al inicio (Fase I) y al final (Fase II) para comprobar la evolución operada en las inteligencias de los sujetos.

Tabla 1. Distribución de la muestra $(\mathrm{N}=101)$ atendiendo a las variables curso y sexo

\begin{tabular}{lccccc}
\hline \multirow{2}{*}{ Curso/Sexo } & \multicolumn{2}{c}{ Niños } & \multicolumn{2}{c}{ Niñas } & \multirow{2}{*}{ Total } \\
\cline { 2 - 5 } & Participantes & G.C. & Participantes & G.C. & \\
\hline Primero de Primaria & $20(48.8 \%)$ & $5(50.0 \%)$ & $17(42.5 \%)$ & $5(50.0 \%)$ & $47(46.5 \%)$ \\
\hline Segundo de Primaria & $21(51.2 \%)$ & $5(50.0 \%)$ & $23(57.5 \%)$ & $5(50.0 \%)$ & $54(53.4 \%)$ \\
\hline Total & $41(50.6 \%)$ & $10(50.0 \%)$ & $40(49.4 \%)$ & $10(50.0 \%)$ & $101(100.0 \%)$ \\
\hline
\end{tabular}

\section{Instrumentos}

Parrilla de análisis de contenido del videojuego

Se analizaron exhaustivamente los elementos estéticos, narrativos y técnicos que definen el Naraba World, así como sus 40 misiones, utilizando el instrumento cualitativo de Del Moral (2004), para posteriormente identificar cada misión o tarea con la inteligencia activada, el área temática y los contenidos curriculares específicos del Principado de Asturias abordados.

\section{Cuestionario de Evaluación de Inteligencias Múltiples}

El instrumento utilizado para medir las IM, validado por Prieto y Ferrándiz (2001) integrado por ochenta ítems, -diez por inteligencia-, permitió identificar el nivel inicial y final de los sujetos en cada una, utilizando una escala (1=muy bajo; 2=bajo; 3=alto; 4=muy alto), para posteriormente constatar sus progresos individuales.

\section{Procedimiento}

La investigación adoptó una dualidad metodológica: a) cualitativa, análisis de contenido de las 40 misiones del videojuego para insertarlo en el contexto de aula, atendiendo a las actividades que presenta para activar las dimensiones propias de cada inteligencia y a los 
incentivos multisensoriales que garantizan su jugabilidad. Y, b) cuantitativa, referida al análisis de la experiencia realizada con el videojuego Naraba World en el Centro Escolar Gesta I de Oviedo (Asturias).

Tras analizar los componentes multisensoriales y evaluar las potencialidades educativas del videojuego, se procedió a sistematizar su integración en el aula determinando una hora semanal durante siete meses, en total 25 sesiones, para constatar las IM potenciadas. La Figura 1 muestra el proceso de la investigación y sus fases.

\begin{tabular}{|c|c|c|c|}
\hline $\begin{array}{l}\text { REVISION } \\
\text { BIBLIOGRÁFICA: } \\
\text { videojuegos en las aulas, } \\
\text { inteligencias múltiples y } \\
\text { contexto escolar. } \\
\text { VIDEOJUEGO: } \\
\text { Selección y evaluación } \\
\text { de un videojuego } \\
\text { educativo. Análisis } \\
\text { descriptivo de las } \\
\text { misiones que integra el } \\
\text { videojuego. } \\
\text { Identificación de las } \\
\text { competencias básicas y } \\
\text { su correspondencia con } \\
\text { las inteligencias } \\
\text { múltiples que aborda el } \\
\text { videojuego. }\end{array}$ & $\begin{array}{l}\text { MUESTRA: } \\
\text { Selección de una } \\
\text { muestra de escolares de } \\
\text { educación primaria } \\
\text { (N=101). } \mathrm{N}=80 \\
\text { participantes en la } \\
\text { experiencia. } \mathrm{N}=20 \text { como } \\
\text { grupo de control. } \\
\text { Sesiones formativas del } \\
\text { profesorado participante: } \\
\quad \quad \text { Integración de } \\
\quad \text { videojuegos en } \\
\quad \text { el aula. } \\
\quad \text { Desarrollo de las } \\
\quad \text { Inteligencias } \\
\quad \text { Múltiples } \\
\text { INSTRUMENTO: } \\
\text { Selección del } \\
\text { cuestionario de } \\
\text { Inteligencias Múltiples } \\
\text { (Prieto y Ferrándiz. } \\
\text { 2001) para identificar los } \\
\text { niveles del alumnado. }\end{array}$ & $\begin{array}{l}\text { FASE 1: (octubre) } \\
\text { Primer y segundo curso } \\
\text { de Educación primaria. } \\
\text { TEST: Diagnóstico } \\
\text { inicial de los sujetos. } \\
\text { Nivel en las } 8 \\
\text { inteligencias (Gardner, } \\
\text { 2005) utilizando el } \\
\text { cuestionario dePrieto y } \\
\text { Ferrandiz(2001). } \\
\text { Recogida de } \\
\text { Información } \\
\text { durantela } \\
\text { experiencia: } \\
\text { Observación } \\
\text { participante. } \\
\text { Entrevistas } \\
\text { semi- } \\
\text { estructuradas. } \\
\text { IMPLEMENTACIÓN } \\
\text { DEL VIDEOJUEGO } \\
\text { ENEL AULA }\end{array}$ & $\begin{array}{l}\text { FASE 2: (mayo) } \\
\text { Primer y segundo curso } \\
\text { de Educación primaria. } \\
\text { RETEST: Medida } \\
\text { final tras la } \\
\text { experiencia. } \\
\text { Estudio } \\
\text { comparativo entre } \\
\text { el grupo } \\
\text { experimentaly de } \\
\text { control de la } \\
\text { evolución en los } \\
\text { niveles de las } 8 \\
\text { inteligencias. }\end{array}$ \\
\hline
\end{tabular}

Figura 1. Proceso de implementación del videojuego en el aula

Las tutoras integraron el videojuego en $1^{\circ}$ y $2^{\circ}$ de Primaria relacionando sus actividades y contenidos con los contenidos de las asignaturas de Matemáticas, Conocimiento del Medio y Música y con las IM con las que estaba directamente vinculadas (Inteligencia lógico-matemática, naturalista y musical). De forma transversal, se abordaron otros contenidos curriculares e igualmente se trabajaron el resto de inteligencias. Para lo cual, confeccionaron una guía ad hoc que hacía corresponder cada actividad con los objetivos formativos, los contenidos curriculares y los tipos de inteligencias. Además, registraron el 
nivel de cada alumno en las ocho inteligencias, al inicio de la experiencia (Fase I: Test) y al concluirla, siete meses después (Fase II: Postest), utilizando el cuestionario descrito.

\section{Diseño y análisis de datos}

Se realizó el análisis de datos descriptivo y multivariante para constatar la contribución real del videojuego al incremento de las IM. El tratamiento estadístico (prueba $t$ student) comparó ambas medidas (test-postest), utilizando un grupo de control que permitió identificar la existencia de diferencias significativas, siendo esta técnica recomendada para muestras pequeñas, dado que el GC era de 20 (Hair, Prentice, Cano \& Suárez, 2007). Los estadísticos se estimaron con el $95.0 \%$ de confiabilidad. Se empleó el paquete estadístico SPSS (v.18).

\section{Resultados}

\section{Análisis de contenido del juego}

El videojuego cumplía con unos prerrequisitos básicos, tales como abordar contenidos curriculares de las asignaturas de Matemáticas, Conocimiento del Medio y Música de Primer Ciclo de Educación Primaria de forma lúdica, y contemplar incentivos multisensoriales (recursos narrativos, estéticos y técnicos) que implican y motivan al jugador.

Recursos narrativos: Es una aventura fantástica en tercera persona que recrea escenarios coloristas, bosques, desiertos, volcanes, etc., con criaturas inventadas y personajes mágicos, basada en la metáfora del viaje, donde el jugador explora diferentes islas, transportándose en pompas de jabón, globos, etc., mientras resuelve distintas misiones para avanzar en la historia.

Recursos estéticos y técnicos: Posee una banda sonora adecuada, efectos sonoros, doblaje de gran calidad, animaciones 3D, permite personalizar un avatar, seleccionando el color de ojos, cabello y piel, vestimenta y complementos, con libertad para manejarlo y moverlo. Las misiones poseen gráficos y dibujos atractivos, con un diseño intuitivo que favorece la inmersión del jugador. Posee una duración adecuada e incorpora varios niveles de dificultad según la edad, adaptándose a sus conocimientos. Cada isla contempla una colección de misiones, con mecánicas de juego variadas, que permiten superar retos y ganar una original 
mascota como premio, que contribuye a fidelizar al jugador, activando las IM.

En total, consta de cuarenta misiones que el jugador debe realizar, agrupadas en tres áreas temáticas: conocimiento del medio (19), matemáticas (12) y educación artística (9). Cada una requiere la activación de una o más inteligencias, de forma interrelacionada, apelando a estrategias que potencian en mayor o menor medida las distintas inteligencias (Gardner, 2005).

Tras evaluar el juego se observó que todas las misiones precisaban la activación de varias inteligencias simultáneamente. Todas las misiones requieren de la inteligencia lingüística al utilizar textos orales y escritos en las explicaciones e instrucciones, aunque el videojuego no la trabajaba específicamente pues no abordaba contenidos curriculares específicos de la asignatura de Lengua Castellana. Diecinueve de ellas se enmarcan en la asignatura de conocimiento del medio, donde diecisiete potencian la inteligencia naturalista (Tabla 2) al requerir habilidades de experimentación, observación e investigación, abordar temas de salud, reciclaje, respeto a los seres vivos y la naturaleza.

Tabla 2. Actividades lúdicas relacionadas con el área de Conocimiento del medio

\begin{tabular}{|c|c|c|}
\hline Misión en el videojuego & Contenidos curriculares & $\begin{array}{l}\text { Inteligencia que } \\
\text { desarrolla }\end{array}$ \\
\hline \multicolumn{3}{|l|}{ Tema: Bloque 1. El entorno y su conservación } \\
\hline $\begin{array}{l}\text { ¡Befish!: Bucear para recoger elementos, con } \\
\text { atención al aire que hay para respirar. }\end{array}$ & $\begin{array}{l}\text { Importancia del agua para la vida. Exploración de las } \\
\text { características físicas del agua, mediante los sentidos. }\end{array}$ & \multirow{3}{*}{$\begin{array}{l}\text { Inteligencia } \\
\text { Naturalista, Espacial y } \\
\text { Corporal cinestésica }\end{array}$} \\
\hline $\begin{array}{l}\text { Misión espacial: recoger el mayor número } \\
\text { posible de estrellas en un tiempo determinado. }\end{array}$ & \multirow{2}{*}{$\begin{array}{l}\text { Percepción y descripción de algunos elementos y } \\
\text { fenómenos naturales: la tierra, la luna, las estrellas y el } \\
\text { sol, el día y la noche. }\end{array}$} & \\
\hline $\begin{array}{l}\text { Viajamos en globo: recoger el mayor número } \\
\text { de "soles" en el menor tiempo posible. }\end{array}$ & & \\
\hline $\begin{array}{l}\text { Jugamos con agua: realizar cambios de estado } \\
\text { en una determinada cantidad de agua. }\end{array}$ & $\begin{array}{l}\text { Importancia del agua para la vida. Exploración, a través } \\
\text { de los sentidos, de las características físicas del agua. }\end{array}$ & $\begin{array}{l}\text { Inteligencia } \\
\text { Naturalista }\end{array}$ \\
\hline \multicolumn{3}{|l|}{ Tema: Bloque 2. La diversidad de los seres vivos } \\
\hline $\begin{array}{l}\text { Puzzanimal: realizar un rompecabezas de } \\
\text { cubos hasta conseguir la imagen que está } \\
\text { relacionada con el panel de muestra. }\end{array}$ & \multirow{2}{*}{$\begin{array}{l}\text { Realización de observación directa e indirecta de } \\
\text { animales y plantas (crecimiento, características y } \\
\text { comportamiento). Clasificación según elementos } \\
\text { observables, identificación y denominación. }\end{array}$} & \multirow{5}{*}{$\begin{array}{l}\text { Inteligencia } \\
\text { Naturalista, Corporal- } \\
\text { cinestésica }\end{array}$} \\
\hline $\begin{array}{l}\text { Los animales del palmeral: identificar y } \\
\text { seleccionar distintos animales. }\end{array}$ & & \\
\hline $\begin{array}{l}\text { En el vivero: cuidar plantas, atender sus } \\
\text { necesidades, solucionar problemas planteados. }\end{array}$ & \multirow{3}{*}{$\begin{array}{l}\text { Las relaciones entre los seres humanos, las plantas y los } \\
\text { animales. Cadenas alimenticias. Animales domésticos y } \\
\text { salvajes, plantas silvestres y cultivadas. } \\
\text { Desarrollo de hábitos de cuidado y actitudes de } \\
\text { respecto a los seres vivos. }\end{array}$} & \\
\hline $\begin{array}{l}\text { En el invernadero: cuidar plantas y atender sus } \\
\text { necesidades. }\end{array}$ & & \\
\hline $\begin{array}{l}\text { Cuidamos el huerto: cuidar el huerto y } \\
\text { solucionar los problemas que se plantean. }\end{array}$ & & \\
\hline $\begin{array}{l}\text { Producir para vivir: formar parejas, tríos o } \\
\text { combinaciones de cuatro elementos, según } \\
\text { rango de edad. }\end{array}$ & $\begin{array}{l}\text { Las relaciones entre los seres humanos, las plantas y los } \\
\text { animales. Cadenas alimenticias. Animales domésticos y } \\
\text { salvajes, plantas silvestres y cultivadas. }\end{array}$ & $\begin{array}{l}\text { Inteligencia } \\
\text { Naturalista y Espacial }\end{array}$ \\
\hline ma: Bloque 3. La salud y el desarrollo & nal & \\
\hline
\end{tabular}


Limpieza y salud: formar parejas, tríos o cuartetos, según rango de edad, siguiendo un criterio de lógica temática, no de igualdad.
Identificación y descripción de alimentos de una dieta

Así somos por dentro: completar el esqueleto humano según las indicaciones en cada caso.

Viajamos por los sentidos: seleccionar uno de los cinco sentidos y colocarlo encima del objeto con el que se relaciona. sana. Conocimiento de hábitos alimenticios saludables. Valoración de la higiene personal y vestido, posturas adecuadas, descanso, y buen uso del tiempo libre.

Inteligencia

Naturalista y visual-

espacial

\section{Inteligencia}

Naturalista y visual-

Identificación de las partes del cuerpo humano. espacial

Aceptación del propio cuerpo y del de los demás con Inteligencia

sus limitaciones y posibilidades.

Intrapersonal y visual-

espacial

Circuito arbóreo: construir un puente, saltar evitando obstáculos y recoger recompensas.

Cóctel de frutas: hacer un cóctel con frutas recogidas en el palmeral siguiendo una receta.

Adquisición de hábitos de prevención de enfermedades y accidentes domésticos.

Inteligencia Corporalcinestésica

Identificación y descripción de alimentos diarios Inteligencia
necesarios para una dieta sana. Conocimiento de Naturalista hábitos de alimentación saludables.

Bloque 4. Personas, culturas y organización social

Antepasados: completar un árbol genealógico.

Ayudamos en casa: formar parejas a partir de ciertos elementos y condiciones.
La familia. Relaciones entre sus miembros. Reparto equilibrado de las tareas domésticas y adquisición de responsabilidades.
Inteligencia

Intrapersona

Bloque 6. Materia y energía

¡Limpiamos el mundo! recoger diferentes residuos y clasificarlos en sus contenedores.

¡Becristal!: combinar varios elementos iguales

El problema de los residuos. Reducción, reutilización y

Inteligencia

¡Becristal!: combinar
para conseguir puntos.

reciclaje de objetos y sustancias.

Naturalista

\section{Doce misiones fomentan la inteligencia lógico-matemática a través de la utilización de} números y operaciones, clasificaciones, categorizaciones, sistemas de medida, comparaciones, simetría y geometría (Tabla 3).

Tabla 3. Actividades lúdicas relacionadas con el área de matemáticas

\begin{tabular}{|c|c|c|}
\hline Misión en el videojuego & Contenidos curriculares & $\begin{array}{l}\text { Inteligencia que } \\
\text { desarrolla }\end{array}$ \\
\hline \multicolumn{3}{|l|}{ Bloque 1. Números y operaciones } \\
\hline $\begin{array}{l}\text { Cangrejos bailarines: clasificar cangrejos } \\
\text { según su tipo de movimiento. }\end{array}$ & $\begin{array}{l}\text { Recuento, medida, ordenación y expresión de cantidades } \\
\text { en situaciones de la vida cotidiana. }\end{array}$ & \multirow{6}{*}{$\begin{array}{l}\text { Inteligencia lógico- } \\
\text { matemática }\end{array}$} \\
\hline $\begin{array}{l}\text { Cangrejos traviesos: clasificar y colocar } \\
\text { cangrejos en cajones. }\end{array}$ & \multirow{2}{*}{$\begin{array}{l}\text { Utilización cotidiana de la suma para juntar o añadir; de } \\
\text { la resta para separar o quitar; y de la multiplicación para } \\
\text { calcular un número de veces o como sumas particulares. }\end{array}$} & \\
\hline $\begin{array}{l}\text { iA recoger!: colocar en posición correcta } \\
\text { elementos para completar las secuencias. }\end{array}$ & & \\
\hline ¡Hora de comer!: poner la mesa completando & $\begin{array}{l}\text { Recuento, medida, ordenación y expresión de cantidades } \\
\text { en situaciones cotidianas. }\end{array}$ & \\
\hline los cubiertos de todos los comensales. & $\begin{array}{l}\text { Lectura y escritura de números naturales en letra y con su } \\
\text { grafía. }\end{array}$ & \\
\hline $\begin{array}{l}\text { Vestuario del minero: ordenar en un armario } \\
\text { elementos propios del minero. }\end{array}$ & $\begin{array}{l}\text { Nombrar y determinar el valor de posición de números } \\
\text { hasta tres cifras manejando diferentes recursos didácticos. }\end{array}$ & \\
\hline \multicolumn{3}{|c|}{ Bloque 2. La medida: estimación y cálculo de magnitudes } \\
\hline $\begin{array}{l}\text { Llenamos la despensa: pesar y equilibrar } \\
\text { productos para almacenarlos en la despensa. }\end{array}$ & $\begin{array}{l}\text { Comparación de objetos según longitud, peso/masa o } \\
\text { capacidad, de manera directa o indirecta. }\end{array}$ & $\begin{array}{l}\text { Inteligencia lógico- } \\
\text { matemática y visual- } \\
\text { espacial }\end{array}$ \\
\hline
\end{tabular}


Brebajes y pócimas: mezclar líquidos de colores en recipientes de diferente capacidad hasta conseguir la cantidad requerida de líquido de un determinado color.

La medida del tiempo: ordenar una secuencia temporal de imágenes en una barra equivalente a un día.

\section{Bloque 3: Geometría}

Ilumina la mina: guiar la luz a través de la mina utilizando espejos, hasta completar la iluminación total de la misma.

Peces de colores: ayudar al cuidador del acuario dando de comer a los peces.

Medición con instrumentos y técnicas no convencionales. Curiosidad por conocer y utilizar las medidas de uso cotidiano e interés por la interpretación de mensajes que contengan informaciones sobre medidas.

Uso de las unidades de medida del tiempo: el tiempo cíclico (día, semana, mes y año) y los intervalos de tiempo (lectura del reloj, las horas enteras, las medias).

Uso de vocabulario geométrico para describir itinerarios: líneas abiertas y cerradas; rectas y curvas.

Inteligencia lógicomatemática

Identificación y clasificación de figuras planas en objetos y espacios cotidianos según su apariencia o tamaño.

Identificación y descripción de cuerpos geométricos en objetos comunes, usando vocabulario geométrico básico. Comparación y clasificación de figuras planas y cuerpos geométricos con criterios elementales.

Búsqueda de elementos de regularidad en figuras y cuerpos a partir de la manipulación de objetos.

\begin{tabular}{llll}
\hline $\begin{array}{l}\text { Figuras y formas: organizar un } \\
\text { rompecabezas formado por cubos que giran } \\
\text { cara a cara al "pinchar" sobre ellas, hasta } \\
\text { formar la imagen sugerida en el panel. }\end{array}$ & $\begin{array}{l}\text { sus elementos característicos. } \\
\text { Confianza en las propias posibilidades, curiosidad, } \\
\text { interés y constancia en la búsqueda de soluciones. }\end{array}$ & $\begin{array}{l}\text { Inteligencia lógico- } \\
\text { matemática y visual- } \\
\text { espacial }\end{array}$ \\
\hline Bloque 4: Tratamiento de la información, azar y probabilidad & \\
\hline $\begin{array}{l}\text { Interpretamos lo que vemos: clasificar varios } \\
\text { elementos según diversos criterios. }\end{array}$ & $\begin{array}{l}\text { Descripción verbal, obtención de información cualitativa } \\
\text { e interpretación de elementos significativos de gráficos } \\
\text { sencillos relativos a fenómenos cercanos. }\end{array}$ & $\begin{array}{l}\text { Intemánática y visual- } \\
\text { espacial }\end{array}$ \\
\hline
\end{tabular}

Nueve misiones se enmarcan en la asignatura de educación artística favoreciendo la inteligencia musical al entrenar la percepción auditiva, la discriminación de sonidos, la producción, composición e interpretación musical junto a la memorización y la repetición de ritmos (Tabla 4$)$.

Tabla 4. Actividades lúdicas relacionadas con el área de Educación artística

\begin{tabular}{|c|c|c|}
\hline Misión en el videojuego & Contenidos curriculares & $\begin{array}{l}\text { Inteligencia que } \\
\text { desarrolla }\end{array}$ \\
\hline \multicolumn{3}{|l|}{ Bloque 4. Interpretación musical } \\
\hline $\begin{array}{l}\text { Danza de las diferentes islas: Aduana, } \\
\text { Alba, Areliosa, Grana, Bruna y Feralis: } \\
\text { reproducir con el instrumento propio de } \\
\text { la isla la melodía distintiva del lugar. }\end{array}$ & \multirow{2}{*}{$\begin{array}{l}\text { Exploración lúdica de las posibilidades sonoras y } \\
\text { expresivas de la voz, el cuerpo y los objetos. } \\
\text { Interpretación y memorización de recitados rítmicos y } \\
\text { canciones al unísono. }\end{array}$} & \multirow[t]{2}{*}{ Inteligencia musical } \\
\hline $\begin{array}{l}\text { ¿Repetimos?: reproducir la secuencia } \\
\text { musical que escucha. }\end{array}$ & & \\
\hline $\begin{array}{l}\text { Trabajamos con ritmo: reproducir el } \\
\text { ritmo que le propone un personaje. }\end{array}$ & $\begin{array}{l}\text { Interpretación y memorización de recitados rítmicos y } \\
\text { canciones al unísono. }\end{array}$ & Inteligencia musical \\
\hline $\begin{array}{l}\text { Medusas virtuosas: agrupar medusas } \\
\text { según el sonido que emiten y llevarlas al } \\
\text { estanque correspondiente. }\end{array}$ & $\begin{array}{l}\text { Exploración lúdica de las posibilidades sonoras y } \\
\text { expresivas de la voz, el cuerpo y los objetos. } \\
\text { Interpretación y memorización de recitados rítmicos y } \\
\text { canciones al unísono. }\end{array}$ & $\begin{array}{l}\text { Inteligencia musical y } \\
\text { visual-espacial }\end{array}$ \\
\hline
\end{tabular}

De forma complementaria se desarrollan otras inteligencias, como la inteligencia visoespacial al potenciar la percepción visual, la producción y apreciación artística, la inteligencia 
corporal-cinestésica, mediante el entrenamiento de la motricidad fina al usar el teclado y el ratón para accionar los elementos interactivos. La inteligencia intrapersonal se fomenta al apelar al autocontrol, la autodisciplina y al favorecer la conformación del autoconcepto. Por último, otras misiones se relacionan con la inteligencia intrapersonal mediante la interacción con otros, la resolución de conflictos, la asunción y el conocimiento de los distintos roles sociales y las habilidades de liderazgo.

Así pues, el estudio previo y exhaustivo del serious game evidenció la correspondencia entre las misiones propuestas y los contenidos de Educación Primaria, junto a las inteligencias que potencian explícita o implícitamente, lo cual ayudó a considerar este videojuego adecuado para la investigación. La figura 2 muestra ejemplos de las misiones del juego vinculadas con diferentes áreas curriculares e inteligencias relacionadas.

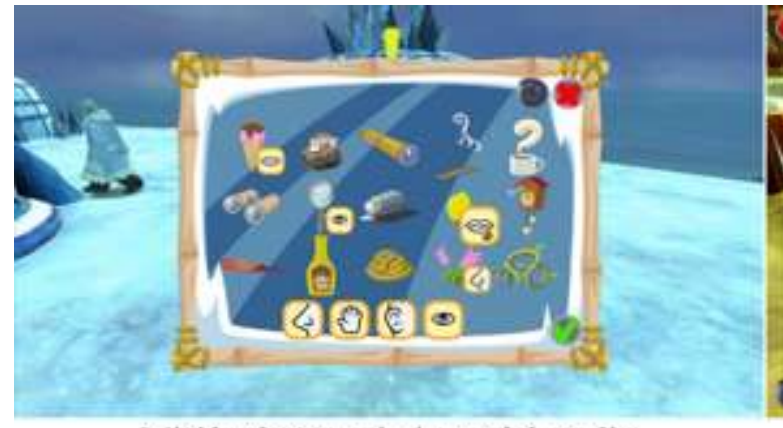

Misión de conocimiento del medio Inteligencia Naturalista

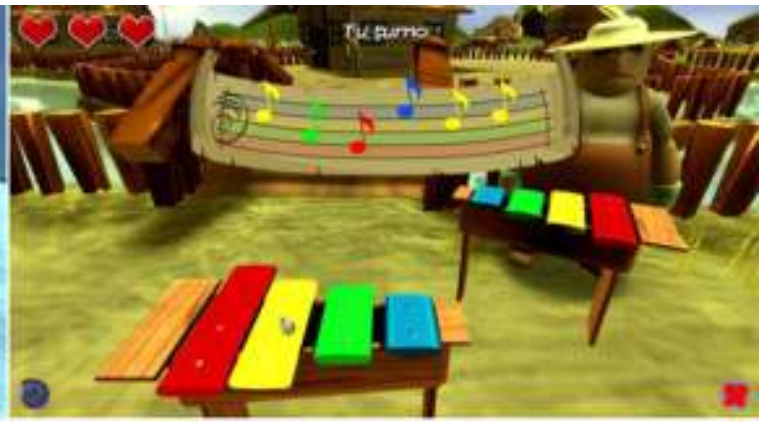

Misión de educación artistica Inteligencia Musical

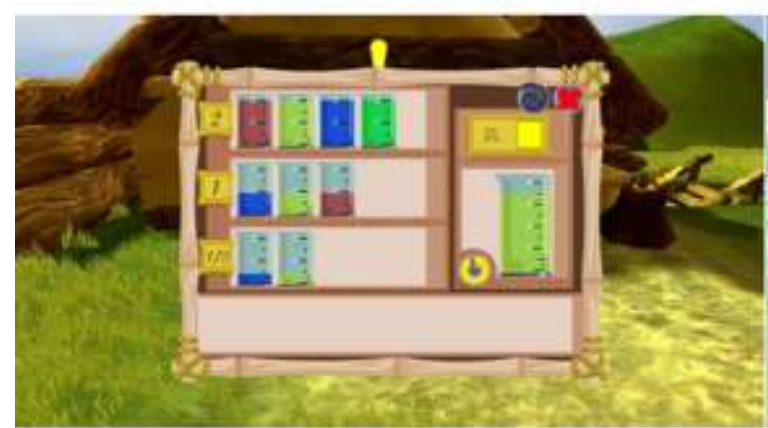

Misión de conocimiento del medio Inteligencia Naturalista
Misión de matemáticas Inteligencia Lógico-matemática

Figura 2. Ejemplos de misiones del videojuego Naraba y su relación con las IM 


\section{Resultados obtenidos a través del Cuestionario de IM}

Tras evaluar las ocho inteligencias -utilizando los 10 indicadores de Prieto y Ferrándiz (2001) para cada una, y estableciendo 4 niveles (1=muy bajo; 2=bajo; 3=alto; 4=muy alto)- se aprecian los logros alcanzados por los escolares en cada inteligencia en ambas fases. La Tabla 5 muestra la distribución porcentual de los sujetos según su nivel, donde las valoraciones del grupo experimental (GE) evidencian un incremento generalizado, disminuyen los de niveles muy bajo y bajo, provocando un desplazamiento hacia los niveles alto y muy alto, destacando especialmente la viso-espacial (21.7\%), e interpersonal (19.6\%).

Tabla 5. Distribución porcentual por niveles de cada inteligencia (GE)

\begin{tabular}{lcccccccc}
\hline \multirow{2}{*}{ Inteligencia } & \multicolumn{4}{c}{$\%$ Fase I } & \multicolumn{3}{c}{$\%$ Fase II } \\
\cline { 2 - 10 } & $\begin{array}{c}\text { Muy } \\
\text { bajo }\end{array}$ & Bajo & Alto & $\begin{array}{c}\text { Muy } \\
\text { alto }\end{array}$ & $\begin{array}{c}\text { Muy } \\
\text { bajo }\end{array}$ & Bajo & Alto & $\begin{array}{c}\text { Muy } \\
\text { alto }\end{array}$ \\
\hline Lingüística & 6.7 & 35.7 & 48.4 & 9.3 & 5.2 & 28.6 & 51.1 & 16.7 \\
\hline Naturalista & 12.1 & 34.6 & 45.4 & 7.9 & 8.2 & 22.1 & 52.8 & 17.7 \\
\hline Matemática & 10.8 & 37.4 & 46.3 & 4.8 & 6.4 & 27.8 & 48.2 & 17.7 \\
\hline Visoespacial & 7.4 & 33.0 & 54.2 & 6.2 & 4.0 & 23.6 & 51.1 & 21.7 \\
\hline Musical & 7.1 & 33.8 & 52.2 & 7.4 & 3.4 & 25.9 & 55.1 & 15.3 \\
\hline Corporal & 8.0 & 37.8 & 47.0 & 7.0 & 5.1 & 27.2 & 49.4 & 18.4 \\
\hline Interpersonal & 10.7 & 28.6 & 50.7 & 9.9 & 6.7 & 20.1 & 54.3 & 19.6 \\
\hline Intrapersonal & 5.9 & 35.5 & 52.1 & 6.4 & 3.7 & 27.4 & 56.3 & 12.2 \\
\hline
\end{tabular}

El contraste de medias de ambas fases evidencia que todas las inteligencias mejoran con el videojuego (Tabla 6 y Figura 3), destacando: Viso-espacial (Media=2.91, SD=0.59), Interpersonal (Media=2.86, $\mathrm{SD}=0.79$ ) y Lingüística (Media=2.86, $\mathrm{SD}=0.55$ ), promocionando a niveles alto y muy alto. Aunque, significativamente sólo la Matemática, Viso-espacial y Corporal-cinestésica.

Tabla 6. Medias de las puntuaciones alcanzadas en cada inteligencia

\begin{tabular}{lcccc}
\hline \multirow{2}{*}{ Inteligencia } & \multicolumn{2}{c}{ Fase inicial } & \multicolumn{2}{c}{ Fase final } \\
\cline { 2 - 5 } & Media & Desv. Est. & Media & Desv. Est. \\
\hline Lingüística & 2.60 & 0.56 & 2.86 & 0.55 \\
\hline Naturalista & 2.49 & 0.65 & 2.80 & 0.66 \\
\hline Matemática & 2.46 & 0.57 & 2.74 & 0.66 \\
\hline Visoespacial & 2.59 & 0.50 & 2.91 & 0.59 \\
\hline Musical & 2.60 & 0.52 & 2.82 & 0.53 \\
\hline Corporal & 2.53 & 0.74 & 2.81 & 0.79 \\
\hline Interpersonal & 2.60 & 0.81 & 2.86 & 0.79 \\
\hline Intrapersonal & 2.59 & 0.70 & 2.77 & 0.71 \\
\hline
\end{tabular}




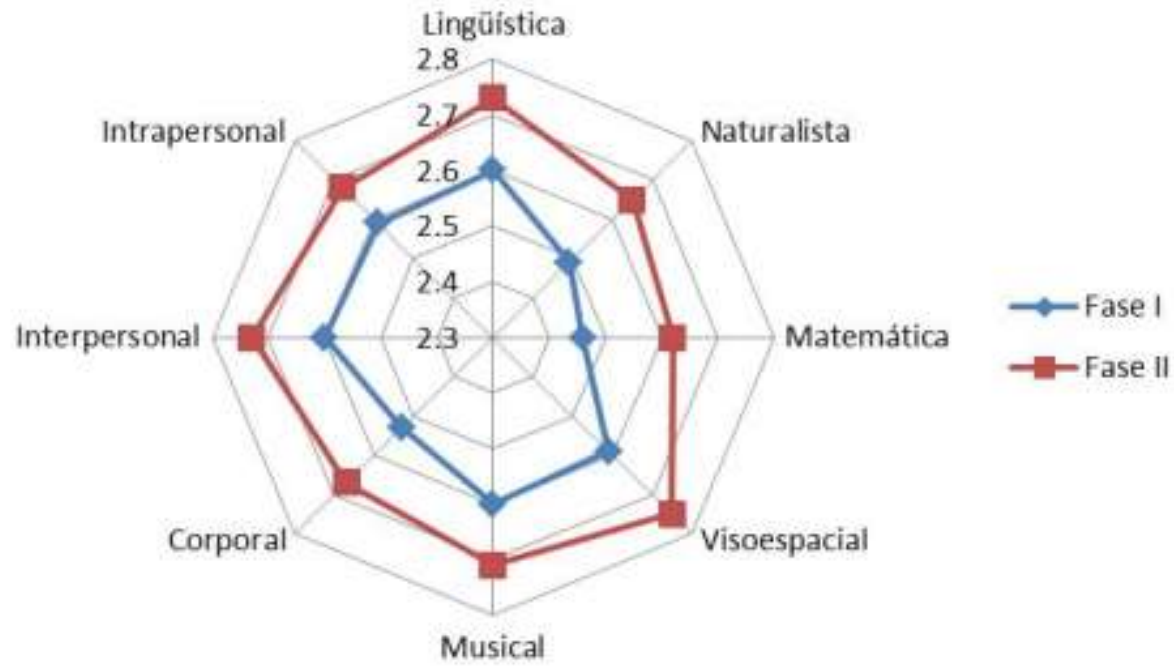

Figura 3. Comparación de las medias de las puntuaciones alcanzadas en ambas fases

A pesar de que la prueba $t$-student detecta la tendencia de mejora de las inteligencias por influencia del videojuego, las diferencias no son significativas entre el GE y GC $(p<.05)$ respecto al curso, aunque sí en función de la variable sexo pero sólo para Viso-espacial $(p<.039)$ y Matemática $(p<.003)$ que mejoran más en las niñas que en los niños. Las demás inteligencias no muestran resultados relevantes, debido a que su $p$ valor indica que no hay ninguna diferencia entre los grupos.

Al realizar un análisis más detallado de los indicadores que conforman cada inteligencia, se detecta que si bien en todas mejoran cualitativamente, al realizar el contraste de medias se evidencia que ese incremento es significativo únicamente en la Matemática, Viso-espacial y Corporal-cinestésica; pues en la Musical e Intrapersonal no lo son. Por ello, a continuación solo se presentan las tablas con la distribución porcentual de los sujetos según el nivel alcanzado en los indicadores que contribuyen a explicar cada una de las inteligencias mejoradas significativamente al concluir la experiencia, evidenciando la influencia positiva del videojuego en el desarrollo de las IM.

En la Fase II, en la Matemática (Tabla 7) se observa una mejoría significativa en los indicadores relacionados con cálculos mentales, gusto por las misiones matemáticas ( $p<.029)$, rompecabezas ( $p<.001)$, secuencias lógicas y estrategias $(p<.033)$, establecimiento de categorías ( $p<.014)$, pensamiento abstracto ( $p<.023)$, y, relación causa-efecto ( $p<.018)$. 
Tabla 7. Distribución porcentual de los sujetos según nivel alcanzado en la Matemática

\begin{tabular}{|c|c|c|c|c|c|c|c|c|}
\hline \multirow[b]{2}{*}{ Ítems de cada Inteligencia } & \multicolumn{4}{|c|}{ Fase I } & \multicolumn{4}{|c|}{ Fase II } \\
\hline & $\begin{array}{l}\text { Muy } \\
\text { bajo }\end{array}$ & Bajo & Alto & $\begin{array}{l}\text { Muy } \\
\text { alto }\end{array}$ & $\begin{array}{l}\text { Muy } \\
\text { bajo }\end{array}$ & Bajo & Alto & $\begin{array}{l}\text { Muy } \\
\text { alto }\end{array}$ \\
\hline 1. Hace muchas preguntas sobre cómo funcionan las cosas & 9.9 & 33.3 & 48.1 & 8.6 & 7.4 & 21.0 & 51.9 & 19.8 \\
\hline $\begin{array}{l}\text { 2. Hace cálculos mentales rápidos para resolver los problemas } \\
\text { aritméticos del videojuego }\end{array}$ & 12.3 & 38.3 & 43.2 & 6.2 & 6.2 & 24.7 & 49.4 & 19.8 \\
\hline 3. Disfruta con las clases de matemáticas & 4.9 & 38.3 & 49.4 & 7.4 & 3.7 & 27.2 & 49.4 & 19.8 \\
\hline 4. Encuentra interesantes las misiones matemáticas del videojuego & 7.4 & 35.8 & 46.9 & 9.9 & 3.7 & 22.2 & 46.9 & 27.2 \\
\hline 5. Le gusta jugar a juegos que requieren usar estrategias & 6.2 & 34.6 & 53.1 & 6.2 & 4.9 & 16.0 & 58.0 & 21.0 \\
\hline 6. Le gusta hacer rompecabezas & 3.7 & 32.1 & 63.0 & 1.2 & 3.7 & 16.0 & 63.0 & 17.3 \\
\hline 7. Le gusta ordenar las cosas estableciendo jerarquías o categorías & 12.3 & 34.6 & 50.6 & 2.5 & 6.2 & 27.2 & 51.9 & 14.8 \\
\hline $\begin{array}{l}\text { 8. Le gusta simular experimentos, y lo hace de modo que demuestra } \\
\text { manejar procesos cognitivos de pensamiento de orden superior }\end{array}$ & 12.3 & 50.6 & 35.8 & 1.2 & 6.2 & 46.9 & 38.3 & 8.6 \\
\hline $\begin{array}{l}\text { 9. Su nivel de pensamiento es más abstracto que el de sus compañeros } \\
\text { de la misma edad }\end{array}$ & 21.0 & 42.0 & 34.6 & 2.5 & 12.3 & 44.4 & 30.9 & 12.3 \\
\hline 10. Para su edad. tiene un buen sentido de la relación causa-efecto & 17.3 & 34.6 & 44.4 & 3.7 & 9.9 & 32.1 & 42.0 & 16.0 \\
\hline
\end{tabular}

En la Viso-espacial (Tabla 8) (Fase II) suben las puntuaciones referidas a la percepción y producción de imágenes mentales o en la pantalla $(p<.002)$, prima lo visual ( $p<.000)$, crea puzzles y laberintos ( $p<.024)$, disfruta dibujando ( $p<.004)$, gusta activar las animaciones ( $p<.021)$, manejo del videojuego ( $p<.021)$, y, descifra y elabora gráficos y diagramas fácilmente $(p<.006)$.

Tabla 8. Distribución porcentual de los sujetos según nivel alcanzado en la Viso-espacial

\begin{tabular}{|c|c|c|c|c|c|c|c|c|}
\hline \multirow[b]{2}{*}{ Ítems de cada Inteligencia } & \multicolumn{4}{|c|}{ Fase I } & \multicolumn{4}{|c|}{ Fase II } \\
\hline & $\begin{array}{l}\text { Muy } \\
\text { bajo }\end{array}$ & Bajo & Alto & $\begin{array}{c}\text { Muy } \\
\text { alto }\end{array}$ & $\begin{array}{l}\text { Muy } \\
\text { bajo }\end{array}$ & Bajo & Alto & $\begin{array}{l}\text { Muy } \\
\text { alto }\end{array}$ \\
\hline $\begin{array}{l}\text { 1. Percibe y produce imágenes mentales, piensa mediante dibujos y } \\
\text { visualiza los detalles más simples }\end{array}$ & 8.6 & 37.0 & 51.9 & 2.5 & 3.7 & 21.0 & 54.3 & 21.0 \\
\hline $\begin{array}{l}\text { 2. Se fija más en las imágenes que ve en pantalla que en los textos } \\
\text { escritos }\end{array}$ & 2.5 & 12.3 & 74.1 & 11.1 & 1.2 & 4.9 & 56.8 & 37.0 \\
\hline 3. Es imaginativo. Ve las cosas de forma diferente a sus compañeros & 11.1 & 44.4 & 35.8 & 8.6 & 4.9 & 37.0 & 39.5 & 18.5 \\
\hline 4. Disfruta con las actividades artísticas & 2.5 & 30.9 & 61.7 & 4.9 & 2.5 & 22.2 & 60.5 & 14.8 \\
\hline $\begin{array}{l}\text { 5. Es capaz de cambiar mentalmente la forma de un objeto y llevarlo a } \\
\text { cabo en la práctica (editar el avatar) }\end{array}$ & 8.6 & 44.4 & 44.4 & 2.5 & 2.5 & 29.6 & 48.1 & 19.8 \\
\hline $\begin{array}{l}\text { 6. Disfruta viendo animaciones y las representaciones visuales del } \\
\text { videojuego }\end{array}$ & 0.0 & 17.3 & 75.3 & 7.4 & 0.0 & 7.4 & 59.3 & 33.3 \\
\hline $\begin{array}{l}\text { 7. Crea representaciones de la información concreta o visual (puzzles } \\
\text { y laberintos del videojuego) }\end{array}$ & 8.6 & 43.2 & 46 & 1.2 & 4.9 & 32.1 & 51.9 & 11.1 \\
\hline $\begin{array}{l}\text { 8. Se interesa y es habilidoso para las tareas que exigen habilidades } \\
\text { viso-espaciales (manejo del videojuego) }\end{array}$ & 8.6 & 33.3 & 48.1 & 9.9 & 6.2 & 24.7 & 43.2 & 25.9 \\
\hline $\begin{array}{l}\text { 9. Tiene facilidad para descifrar y elaborar mapas, esquemas, gráficos } \\
\text { y diagramas }\end{array}$ & 11.1 & 42.0 & 40.7 & 6.2 & 6.2 & 38.3 & 33.3 & 22.2 \\
\hline $\begin{array}{l}\text { 10. Le gusta dibujar en el taller de dibujo del videojuego, así como } \\
\text { colorear, hacer collages... }\end{array}$ & 4.9 & 24.7 & 63.0 & 7.4 & 3.7 & 18.5 & 64.2 & 13.6 \\
\hline
\end{tabular}

Los incrementos significativos en la Corporal-cinestésica al finalizar la experiencia (Tabla 9) se detectan en indicadores relacionados con la manipulación y precisión motriz ( $p<.008)$, simulación de movimientos con el avatar ( $p<.001), \mathrm{y}$, expresión de sensaciones físicas $(p<.006)$, destacándose los mayores incrementos en los niveles alto y muy alto, así: 
$70.3 \%, 77.8 \%, y, 79.0 \%$ respectivamente. No se detectan incrementos significativos en los demás ítems.

Tabla 9. Distribución porcentual de los sujetos según nivel alcanzado en la Corporal-Cinestésica

\begin{tabular}{|c|c|c|c|c|c|c|c|c|}
\hline \multirow{2}{*}{ Ítems de cada Inteligencia } & \multicolumn{4}{|c|}{ Fase I } & \multicolumn{4}{|c|}{ Fase II } \\
\hline & $\begin{array}{l}\text { Muy } \\
\text { bajo }\end{array}$ & Bajo & Alto & $\begin{array}{l}\text { Muy } \\
\text { alto }\end{array}$ & $\begin{array}{l}\text { Muy } \\
\text { bajo }\end{array}$ & Bajo & Alto & $\begin{array}{l}\text { Muy } \\
\text { alto }\end{array}$ \\
\hline 1. Destaca en los deportes & 7.4 & 44.4 & 33.3 & 14.8 & 3.7 & 42.0 & 30.9 & 23.5 \\
\hline $\begin{array}{l}\text { 2. Se mueve de manera rítmica y manipula objetos cuando tiene que } \\
\text { estar sentado en un mismo lugar mucho tiempo }\end{array}$ & 7.4 & 35.8 & 46.9 & 9.9 & 3.7 & 32.1 & 43.2 & 21.0 \\
\hline 3. Imita de manera inteligente los gestos y modales de otras personas & 13.6 & 32.1 & 49.4 & 4.9 & 9.9 & 30.9 & 50.6 & 8.6 \\
\hline 4. Le entusiasma desarmar las cosas y después volverlas a armar & 12.3 & 44.4 & 38.3 & 4.9 & 8.6 & 38.3 & 42.0 & 11.1 \\
\hline $\begin{array}{l}\text { 5. Le gusta manipular cosas (en cuanto al videojuego, manipular el } \\
\text { ratón y el teclado) }\end{array}$ & 7.4 & 35.8 & 46.9 & 9.9 & 4.9 & 23.5 & 42.0 & 29.6 \\
\hline $\begin{array}{l}\text { 6. Le gusta correr, saltar en la realidad, y simular esos mismos } \\
\text { comportamientos con su avatar }\end{array}$ & 8.6 & 27.2 & 59.3 & 4.9 & 0.0 & 17.3 & 51.9 & 25.9 \\
\hline $\begin{array}{l}\text { 7. Demuestra habilidad y precisión motriz con los periféricos de } \\
\text { ordenador }\end{array}$ & 6.2 & 42.0 & 39.5 & 12.3 & 4.9 & 24.7 & 40.7 & 29.6 \\
\hline 8. Se expresa con gestos para decir lo que piensa & 6.2 & 40.7 & 50.6 & 2.5 & 3.7 & 17.3 & 70.4 & 8.6 \\
\hline $\begin{array}{l}\text { 9. Expresa diferentes sensaciones físicas mientras trabaja con el } \\
\text { videojuego }\end{array}$ & 6.2 & 46.9 & 45.6 & 1.2 & 3.7 & 27.2 & 53.1 & 16.0 \\
\hline 10. Le gustan las actividades manuales & 4.9 & 28.4 & 61.7 & 4.9 & 2.5 & 18.5 & 69.1 & 9.9 \\
\hline
\end{tabular}

En la Lingüística los indicadores relacionados con la escritura, la lectura, las habilidades causa-efecto, el disfrute con las narraciones y las simulaciones del videojuego, la buena memoria y la comunicación oral son los que contribuyen al incremento de esta inteligencia. Sin embargo, solo se detectó significativo el gusto por las rimas, los trabalenguas... $(p<.042)$, que no pueden atribuirse al videojuego dado que no hay misiones sobre estas cuestiones.

En la Naturalista, se detecta mejoría en los indicadores asociados con el disfrute del videojuego, la curiosidad, la simulación, la comparación y la clasificación, pero solo resulta significativo el relacionado con tener gran conocimiento sobre temas relacionados con la ciencia $(p<.032)$. En la Interpersonal mejoran significativamente los relacionados con su capacidad empática y ayuda a los demás ( $p<.007$ ). En la Musical, a pesar de que mejoran los indicadores relativos al recuerdo de melodías, habilidad para componer y gusto por la música, y de contar con misiones en el videojuego relacionadas con la música y su forma rítmica de hablar o moverse, y el reconocimiento del tono de la música, el incremento no es estadísticamente significativo.En la Intrapersonal se observan incrementos en los indicadores como ser conscientes de sus emociones, trabajar con autonomía, tener claros sus objetivos, gusto por trabajar individualmente, aunque tampoco son significativos. 


\section{Discusión y conclusiones}

El videojuego seleccionado puede considerarse un valioso catalizador para potenciar el desarrollo de las IM en los escolares de primaria, cuya implementación en el aula requirió de un estudio concienzudo previo para amplificar su eficiencia. Este trabajo coincide con los resultados obtenidos en investigaciones similares al relacionar el uso de videojuegos con el desarrollo efectivo de las Inteligencias Múltiples (Chuang \& Su, 2012; Li, Ma \& Ma, 2012).

La experiencia llevada a cabo de integración escolar de videojuegos educativos ha puesto de relieve que éstos pueden constituir contextos de aprendizaje en sí mismos y favorecer el desarrollo de las Inteligencias Múltiples, siempre que cumplan una serie de requisitos educativos tales como: abordar contenidos curriculares y propiciar el entrenamiento de habilidades y el desarrollo de competencias. Además de aprovechar su potencial lúdico y orientar sus incentivos multisensoriales al servicio del aprendizaje. Para ello, resulta clave la selección previa del videojuego mediante: el análisis del contenido de las misiones o actividades que incluya, la evaluación de su adecuación a los contenidos curriculares de primaria, así como la identificación de oportunidades que ofrece para potenciar las IM. Además, desde el punto de vista lúdico, los componentes multisensoriales del videojuego (recursos narrativos, estéticos y técnicos) deben invitar al alumnado a implicarse en la historia propuesta y garantizar su empatía mediante incentivos que favorezcan sus deseos de superación y diversión (Ritterfeld, Cody \& Vorderer, 2009).

Concretamente, el videojuego Naraba World, integrado por misiones estrechamente relacionadas con las áreas curriculares de primaria, facilitó la adquisición y el entrenamiento de habilidades y destrezas muy diversas, especialmente promovía la activación de la inteligencia Matemática a partir de juegos de recuento, medida, cantidades series, secuencias lógicas, equivalencias, tamaños, formas, etc.; la inteligencia Naturalista, a través la descripción de partes del cuerpo humano, promoción de hábitos de alimentación saludables, experimentación, observación de la naturaleza, estudio de formas de vida animal y vegetal, etc.; las inteligencias Musical y Viso-espacial mediante ritmos, recitado de melodías, ordenación de formas en el espacio, exploración lúdica de las posibilidades sonoras y expresivas de la voz, el cuerpo y los objetos, etc. La inteligencia Lingüística se potenciaba implícitamente con todas las misiones puesto que precisaba de las comprensión de los diversos lenguajes (oral, visual, textual, gráfico, multimedia, etc.), aunque no existían 
actividades específicas para trabajar dicha inteligencia de forma explícita. Numerosas misiones activaban varias inteligencias simultáneamente, de manera coordinada, priorizando unas en mayor medida que otras.

La implementación del videojuego en el aula permitió evaluar el incremento de las ocho inteligencias, operado en el alumnado tras participar en la experiencia, observándose un aumento generalizado de todas, pero destacando significativamente la Lógico-matemática debido a la tipología de actividades que propician su entrenamiento en mayor medida, pues muchas misiones fomentan la categorización, secuenciación, cálculos mentales y rompecabezas. Del mismo modo, la Viso-espacial y la Corporal-cinestésica obtuvieron resultados óptimos dado el formato del videojuego, la ejecución de algunas misiones precisa de habilidades de discriminación visual (formas y tamaño de objetos), activar animaciones, gráficos y dibujos. Las actividades que fomentan el cuidado del cuerpo (dieta saludable e higiene personal) presentadas de forma lúdica facilitan el aprendizaje. Además, el uso de periféricos para mover objetos y desplazarlos en la pantalla, exige precisión y una manipulación motriz adecuada para simular los movimientos del juego, lo que sin duda contribuye a su entrenamiento.

Asimismo, y si bien el videojuego no proponía misiones específicas orientadas a activar la inteligencia Interpersonal, se observó un incremento significativo en los indicadores referidos al desarrollo de la capacidad empática y a la potenciación de ayuda a los demás, pues en la experiencia en el aula, los niños se ayudaban unos a otros durante el juego, especialmente en las misiones más complicadas, generándose un ambiente de juego colaborativo muy enriquecedor, minimizando incluso las conductas disruptivas y provocando un intercambio de roles, pues los alumnos más expertos en el videojuego coincidió que eran los más distraídos en las clases convencionales, sintiéndose más reconocidos por sus compañeros al prestarles su apoyo en la resolución de los problemas planteados por el juego.

Por otro lado, se pudo constatar que las niñas resultaron ser las más beneficiadas con la experiencia apoyada en el videojuego puesto que mejoran significativamente en las inteligencias Viso-espacial y Matemática más que los niños. Las operaciones de medida, cálculos matemáticos, recuentos, identificación y clasificación de formas y tamaños, relaciones y correspondencias, etc., presentados de forma lúdica mediante animaciones, 
gráficos y dibujos, junto a las actividades que fomentan el cuidado del cuerpo (dieta saludable e higiene personal) facilitan el aprendizaje e incrementan las IM.

Hay que subrayar que para que el videojuego se convirtiera en un catalizador capaz de activar las IM en escolares de primaria, se precisó de una rigurosa selección y del análisis de contenido previo, tanto desde la perspectiva lúdica, evaluando la calidad de los recursos narrativos, estéticos y técnicos que presenta; como desde la vertiente educativa, estudiando las misiones o actividades que promueve para acoplarlo al currículo, adoptando las medidas didácticas y organizativas necesarias para garantizar su eficiencia al implementarlo en el aula.

Finalmente, se puede concluir que los videojuegos educativos pueden contribuir al logro de numerosos aprendizajes a partir de las misiones que proponen, activando simultáneamente todas las inteligencias. Indudablemente, esto plantea un nuevo reto a los docentes, pues deben aprender a explotar el potencial de estos instrumentos propios del contexto de ocio, con los que los alumnos cada vez están más familiarizados, para convertirlos en herramientas didácticas al servicio del aprendizaje.

En un futuro se ve necesario ampliar el tamaño de la muestra y experimentar con otros serious games más completos, pues el videojuego elegido no contaba con actividades específicas para trabajar la asignatura de Lengua Castellana, lo que impidió constatar el incremento en la inteligencia lingüística al no trabajarse de forma explícita aunque si lo hacía implícitamente dado que las misiones se presentaban por escrito y debían comprenderse sus enunciados. Asimismo, se podría replicar la experiencia en el contexto sanitario o en escenarios de educación no formal, de modo que se pudiera reafirmar el potencial de los videojuegos como catalizadores de las IM. 


\section{Referencias}

Acampora, G., Loia, V. \& Vitiello, A. (2012). Improving game bot behaviours through timed emotional intelligence. Knowledge-Based Systems, 34, 97-113. doi:10.1016/j.knosys.2012.04.012

Adams, D. M. \& Clark, D. B. (2014). Integrating self-explanation functionality into a complex game environment: Keeping gaming in motion. Computers \& Education, 73, 149-159. doi:10.1016/j.compedu.2014.01.002

Amstrong, T. (2009). Multiple intelligences in the classroom. United States of America: ASCD publications.

Annetta, L. A., Minogue, J., Holmes, S. Y., \& Cheng, M.T. (2009). Investigating the impact of video games on high school students' engagement and learning about genetics. Computers and Education, 53(1), 74-85. doi:10.1016/j.compedu.2008.12.020

Antunes, C. (2005). Estimular las Inteligencias Múltiples. Madrid: Narcea.

Bailey, K., \& West, R. (2013). The effects of an action video game on visual and affective information processing. Brain Research, 1504, 35-46. doi:10.1016/j.brainres.2013.02.019

Bailey, R., Wise, K. \& Bolls, P. (2009). How avatar customizability affects children's arousal and subjective presence during junk food-sponsored online video games. CyberPsychology and Behavior, 12(3), 277-283. doi:10.1089/cpb.2008.0292

Basak, C., Boot, W. R., Voss, M.W., \& Kramer, A. F. (2008). Can training in a real-time strategy video game attenuate cognitive decline in older adults? Psychology \& Aging, 23(4), 765-777.

Castronova, E. (2006). On the Research Value of Large Games: Natural Experiments in Norrath and Camelot. Games \& Culture, 2(1), 163-186.

Chang, K. E., Wu, L. J., Weng, S. E., \& Sung, Y. T. (2012). Embedding game-based problem-solving phase into problem-posing system for mathematics learning. Computers \& Education, 58(2), 775-786.

Chuang, T., \& Su, S. (2012). Using mobile console games for multiple intelligences and education. International Journal of Mobile Learning and Organisation, 3(6), 204-217. doi: 10.1504/IJMLO.2012.050047

Connolly, T. M., Boyle, E. A., MacArthur, E., Hainey, T., \& Boyle, J. M. (2012). A systematic literature review of empirical evidence on computer games and serious games. Computers \& Education, 59(2), 661-686. doi:10.1016/j.compedu.2012.03.004

Cortés, S., García, M. R., \& Lacasa, P. (2012). Videojuegos y Redes Sociales. El proceso de 
identidad en Los Sims 3. Revista de Educación a Distancia (RED), 33. Retrieved from http://www.um.es/ead/red/33

Deater-Deckard, K., Chang, M., \& Evans, M. E. (2013). Engagement states and learning from educational games. In F. C. Blumberg \& S. M. Fisch (Eds.), Digital Games: A Context for Cognitive Development. New Directions for Child and Adolescent Development, 139, 21-30.

Del Castillo, H., Herrero, D., García, A. B., Checa, M., \& Monjelat, N. (2012). Desarrollo de competencias a través de los videojuegos deportivos: alfabetización digital e identidad. Revista de Educación a Distancia (RED), 33. Retrieved from http://www.um.es/ead/red/33

Del Moral, M. E. (2004). Pautas procedimentales para el diseño y análisis de videojuegos desde una perspectiva educativa. In Del Moral, M.E. (Coord.). Sociedad del conocimiento, ocio y cultura: un enfoque interdisciplinar. (pp. 407-426). Oviedo: Ediciones KRK.

Del Moral, M.E. \& Guzmán, A.P. (2014). CityVille: collaborative game play, communication and skill development in social networks. Journal of New Approaches in Educational Research, 3(1), 11-19. Retrieved from http://naerjournal.ua.es/article/view/v3n1-2 doi:10.7821/naer.3.1.11-19

DiCerbo, K. E. (2014). Game-Based Assessment of Persistence. Educational Technology \& Society, 17(1), 17-28.

Echeverría, A., García-Campo, C., Nussbaum, M., Gil, F., Villalta, M., Améstica, M., \& Echeverría, S. (2011). A framework for the design and integration of collaborative classroom games. Computers \& Education, 57(1), 1127-1136.

Esteban, I., Martínez, F. J. Huertas, R., Meseguer, A., \& Rodríguez, I. (2014). Modelling students' flow experiences in an online learning environment. Computers \& Education, 71, 111-123. doi:10.1016/j.compedu.2013.09.012

Fogarty, R., \& Stoehr, J. (2008). Integrating curricula with multiple intelligences: Teams, themes \& threads. Thousand Oaks, California: Corwin Press.

Gardner, H. (2005). Inteligencias múltiples. La teoría en la práctica. Barcelona: Paidós.

Garris, R., Ahlers, R., \& Driskell, J. E. (2002). Games, motivation. And learning: a research and practice model. Simulation \& Gaming, 33(4), 441-467. doi: $10.1177 / 1046878102238607$

Graf, D.L., Pratt, L.V., Casey, N., Hester, C.N., \& Short, K.R. (2009). Playing active video games increases energy expenditure in children. Pediatrics, 124(2), 534-540. 
Greenfield, P. M. (2009). Technology and informal education: What is taught, what is learned. Science, 323(2), 69-71. doi:10.1126/science.1167190

Greitemeyer, T. \& Osswald, S. (2010). Effects of prosocial video games on prosocial behavior. Journal of Personality \& Social Psychology, 98(2), 211-221.

Hair, J. F., Prentice, E., Cano, D., \& Suárez, M. G. (2007). Análisis Multivariante. 5 $5^{\mathrm{a}}$ ed. Madrid: Prentice Hall.

Herodotou, C., Kambouri, M. \& Winters, N. (2011). The role of trait emotional intelligence in gamers' preferences for play and frequency of gaming. Computers in Human Behavior, 27(5), 1815-1819. doi:10.1016/j.chb.2011.04.001

Hickey, D., Ingram-Goble, A. \& Jameson, E. (2009). Designing assessments and assessing designs in virtual educational environments. Journal of Science Education and Technology, 18(2), 187-208. doi:10.1007/s10956-008-9143-1

Islas, C., Leendertz, V., Vinni, M., Sutinen, E., \& Ellis, S. (2013). Hypercontextualized Learning Games: Fantasy, Motivation, and Engagement in Reality. Simulation Gaming, 44(6), 821-845. doi:10.1177/1046878113514807

Korallo, L., Foreman, N., Boyd-Davis, S., Moar, M., \& Coulson, M. (2012). Do challenge, task experience or computer familiarity influence the learning of historical chronology from virtual environments in 8-9 year old children? Computers \& Education, 58(4), 1106-1116. doi:10.1016/j.compedu.2011.12.011

Lee, Y., Heeter, C., Magerko, B., \& Medler, B. (2012). Gaming Mindsets: Implicit Theories in Serious Game Learning. Cyberpsychology, behavior, and social networking, 15(4), 190-194. doi: 10.1089/cyber.2011.0328

Li, J., Ma, S., \& Ma, L. (2012). The Study on the Effect of Educational Games for the Development of Students' Logic-mathematics of Multiple Intelligence. Physics Procedia, 33, 1749-1752. doi: 10.1016/j.phpro.2012.05.280

Lin, H. \& Wang, H. (2014). Avatar creation in virtual worlds: Behaviors and motivations. Computers in Human Behavior, 34, 213-218. doi: 10.1016/j.chb.2013.10.005

Liu, C., Cheng, Y. \& Huang, C. (2011). The effect of simulation games on the learning of computational problem solving. Computers \& Education, 57(3), 1907-1918. doi: 10.1016/j.compedu.2011.04.002

Llorca, M. A. (2009). Hábitos y uso de los videojuegos en la comunicación visual: influencia en la inteligencia espacial y el rendimiento (Tesis inédita). Universidad de Granada. Granada.

Micronet (2010). Naraba World. Retrieved from http://www.narabaworld.com 
Papastergiou, M. (2009). Exploring the potential of computer and video games for health and physical education: A literature review. Computers \& Education, 53(3), 603-622. doi:10.1016/j.compedu.2009.04.001

Pindado, J. (2005). Las posibilidades educativas de los videojuegos. Una revisión de los estudios más significativos. Pixel-Bit. Revista de Medios y Educación, 26, 55-67.

Prieto, M. D. \& Ballester, P. (2003). Las inteligencias múltiples. Diferentes formas de enseñar y aprender. Madrid: Ediciones Pirámide.

Prieto, M. D. \& Ferrándiz, C. (2001). Inteligencias múltiples y currículum escolar. Málaga: Ediciones Aljibe.

Riha, M. \& Robles-Piña, R.A. (2009). The Influence of Multiple Intelligence Theory on WebBased Learning. MERLOT. Journal of Online Learning \& Teaching, 5(1), 97-103. Retrieved from http://jolt.merlot.org/vol5no1/robles-pina_0309.pdf

Ritterfeld, U., Cody, M., \& Vorderer, P. (Eds.). (2009). Serious games: Mechanisms and effects. London: Routledge.

Robertson, J. (2013). The influence of a game-making project on male and female learners' attitudes to computing. Computer Science Education, 23(1), 58-83.

Sanford, K., \& Madill, L. (2007). Understanding the Power of New Literacies through Video Game Play and Design. Canadian Journal of Education, 30(2), 432-455.

Saricaoglu, A., \& Arikan, A. (2009). A study of multiple intelligences, foreign language success and some selected variables. Journal of Theory \& Practice in Education, 5(2), 110-122.

Retrieved from http://www.bcl.edu.ar/spip/IMG/pdf/asaricaoglu_aarikan12.pdf

Schaaf, R. (2012). Does digital game based learning improve student time-on-task behavior and engagement in comparison to alternative instructional strategies? Canadian Journal of Action Research, 13(1), 50-64. Retrieved from http://cjar.nipissingu.ca/index.php/cjar/article/view/30/27

Schollmeyer, J. (2006). Games get serious. Bulletin of the Atomic Schientist, 62(4), 34-39.

Sherry, J. L. (2013). The challenge of audience reception: A developmental model for educational game engagement. In F. C. Blumberg \& S. M. Fisch (Eds.), Digital Games: A Context for Cognitive Development. New Directions for Child and Adolescent Development, 139, 11-20.

Sung, H. \& Hwang, G. (2013). A collaborative game-based learning approach to improving students' learning performance in science courses. Computers \& Education, 63(1), 4351. doi:10.1016/j.compedu.2012.11.019 
Voogt, J., \& Pareja, N. (2010). 21st century skills. Discussion paper. Universiteit Twente. Retrieved from:

http://opite.pbworks.com/w/file/fetch/61995295/White\%20Paper\%2021stCS_Final_E NG_def2.pdf

Vos, N., van der Meijden, H., \& Denessen, E. (2011). Effects of constructing versus playing an educational game on student motivation and deep learning strategy use. Computers \& Education, 56(1), 127-137. doi:10.1016/j.compedu.2010.08.013

Wouters, P., van Nimwegen, C., van Oostendorp, H., \& van der Spek, E. (2013). A MetaAnalysis of the Cognitive and Motivational Effects of Serious Games. Journal of Educational Psychology, 105(2), 249-265. doi:10.1037/a0031311

Yang, J. C., \& Chen, S. Y. (2010). Effects of gender differences and spatial abilities within a digital pentominoes game. Computers \& Education, 55(3), 1220-1233. doi:10.1016/j.compedu.2010.05.019 
$\mathrm{M}^{\mathrm{a}}$ Esther del Moral Pérez et al.

[Página en blanco por razones de paginación]

- 270 - $\quad$ Electronic Journal of Research in Educational Psychology, 13(2), 243-270. ISSN: 1696-2095. 2015, no. 36 http://dx.doi.org/10.14204/ejrep.36.14091 